\title{
Natural Pigments and Biogas Recovery from Microalgae Grown in Wastewater
}

\author{
Larissa T. Arashiro, Ivet Ferrer,* Catalina C. Pániker, Juan Luis Gómez-Pinchetti, \\ Diederik P. L. Rousseau, Stijn W. H. Van Hulle, and Marianna Garfí
}

Cite This: ACS Sustainable Chem. Eng. 2020, 8, 10691-10701

Read Online

\section{ACCESS \\ 山ll Metrics \& More \\ Article Recommendations \\ Supporting Information}

ABSTRACT: This study assessed the recovery of natural pigments (phycobiliproteins) and bioenergy (biogas) from microalgae grown in wastewater. A consortium of microalgae, mainly composed by Nostoc, Phormidium, and Geitlerinema, known to have high phycobiliproteins content, was grown in photobioreactors. The growth medium was composed by secondary effluent from a high rate algal pond (HRAP) along with the anaerobic digestion centrate, which aimed to enhance the $\mathrm{N} / \mathrm{P}$ ratio, given the lack of nutrients in the secondary effluent. Additionally, the centrate is still a challenging anaerobic digestion residue since the high nitrogen concentrations have to be removed before disposal. Removal efficiencies up to $52 \%$ of $\mathrm{COD}, 86 \%$ of $\mathrm{NH}_{4}{ }^{+}-\mathrm{N}$, and $100 \%$ of phosphorus were observed. The biomass composition was monitored over the experimental period in order to ensure stable cyanobacterial dominance in the mixed culture. Phycocyanin and phycoerythrin were extracted from harvested

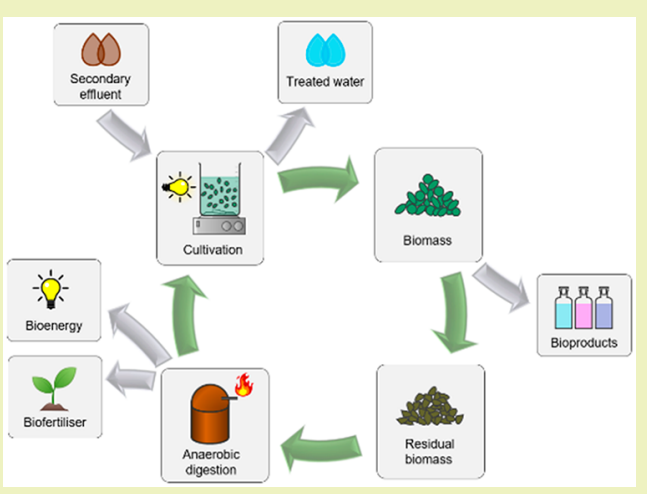
biomass, achieving maximum concentrations of 20.1 and $8.1 \mathrm{mg} / \mathrm{g}$ dry weight, respectively. The residual biomass from phycobiliproteins extraction was then used to produce biogas, with final methane yields ranging from 159 to $199 \mathrm{~mL} \mathrm{CH}_{4} / \mathrm{g}$ VS. According to the results, by combining the extraction of pigments and the production of biogas from residual biomass, we would not only obtain high-value compounds, but also more energy (around 5-10\% higher), as compared to the single recovery of biogas. The proposed process poses an example of resource recovery from biomass grown in wastewater, moving toward a circular bioeconomy.

KEYWORDS: bioproduct, centrate, circular economy, cyanobacteria, high rate algal pond, photobioreactor, phycobiliproteins, resources recovery

\section{INTRODUCTION}

Over the past 50 years, the cultivation of microalgae and cyanobacteria in wastewater has been widely proposed as a sustainable alternative for biomass production and valorization (e.g., natural pigments and biofertilizer production), while improving water quality. ${ }^{1,2}$ These microorganisms can not only recycle nutrients present in wastewater, but also reduce energy consumption by providing oxygen for bacterial degradation, presenting substantial environmental benefits. ${ }^{3}$ Among the functional components identified in cyanobacteria, natural pigments have received particular attention due to their potential use in different industries, such as pharmaceutical, food, cosmetics, and textile. ${ }^{4}$ The main photosynthetic pigments in cyanobacteria are chlorophylls, carotenoids, and phycobilins. Phycobilins are tetrapyrrole prosthetic groups with linear discs constituted by phycobiliproteins, which act as auxiliary pigments exclusive to cyanobacteria, red algae, and cryptomonads. ${ }^{5}$ Depending on their composition and content of chromophores, phycobiliproteins may be classified as phycocyanins $\left(\lambda_{\max }=610-625\right.$ $\mathrm{nm})$, phycoerythrins $\left(\lambda_{\max }=490-570 \mathrm{~nm}\right)$, or allophycocya- nins $\left(\lambda_{\max }=650-660 \mathrm{~nm}\right) .{ }^{6}$ Commercially, phycobiliproteins are high-value natural products with existing or potential biotechnological applications in nutraceuticals and pharmaceuticals, food and cosmetic industries, as well as biomedical research and clinical diagnostics. ${ }^{7,8}$

The production of phycobiliproteins generates residual biomass that can be used as biofertilizer or to recover bioenergy through biogas production. ${ }^{9,10}$ In this case, a typical mix of low volume high-value products (such as pigments) and high volume low-value products (such as bioenergy) is produced. $^{11}$ The high-value products provide economic feasibility while the low-value products can supply or minimize the energy demand of the system. ${ }^{12,13}$ In this context, some studies have investigated the cultivation of

Received: February 10, 2020

Revised: $\quad$ May 5, 2020

Published: June 15, 2020 


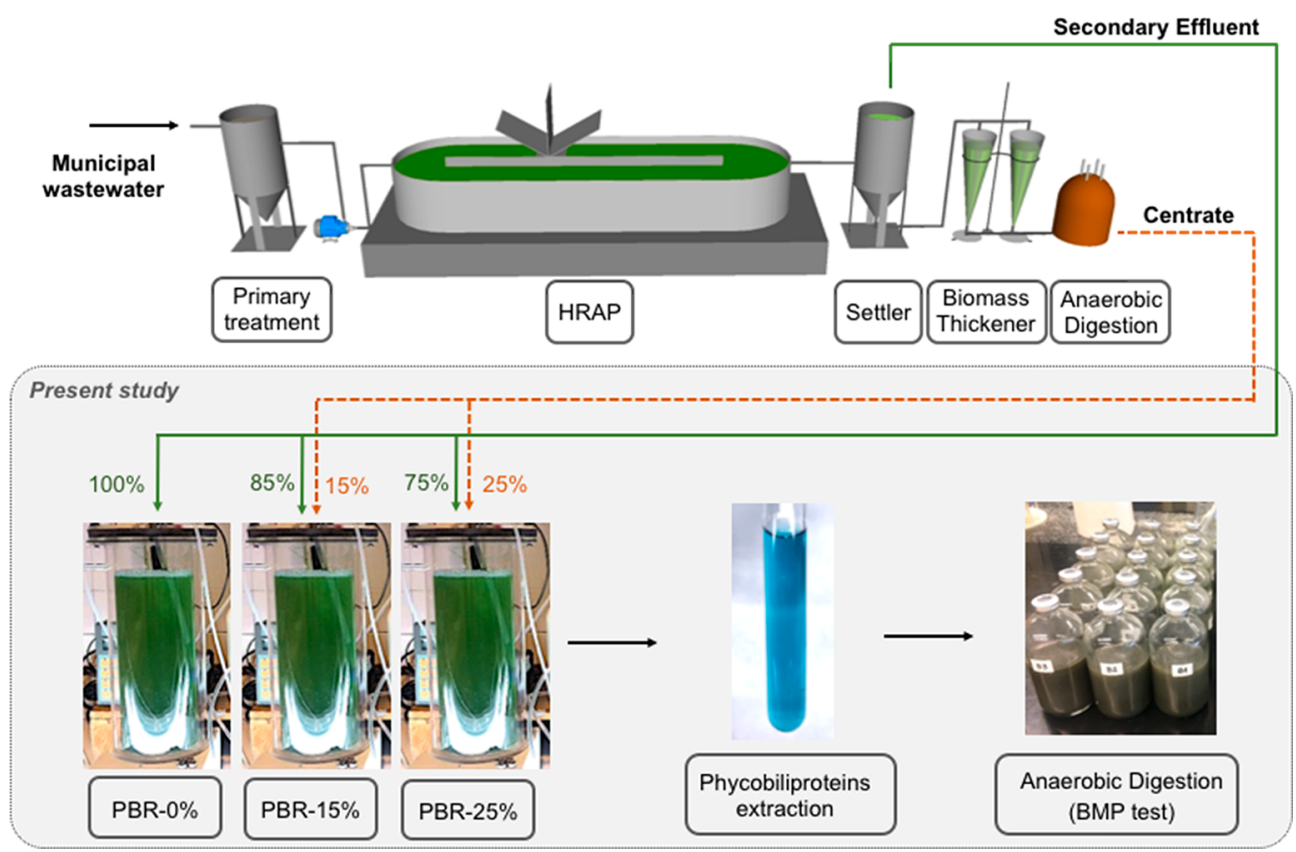

Figure 1. Scheme of the microalgae-based wastewater treatment pilot plant located at UPC, Barcelona, Spain (previously described by Arashiro et $\mathrm{al}^{25}$ ) and the experimental setup described in this study.

microalgae in wastewater, in order to minimize costs of biomass production, followed by phycobiliproteins extraction from the biomass. ${ }^{11,14-16}$

Digestate from anaerobic digesters has become a major bottleneck in the development of the biogas industry, in which the solid phase is often used as agricultural biofertilizer, while the disposal of liquid phase (centrate) is still a great challenge. ${ }^{17}$ In this sense, previous researchers investigated the use of centrate diluted in synthetic medium, secondary/ tertiary wastewater, or seawater, in order to mitigate $\mathrm{NH}_{4}{ }^{+}-\mathrm{N}$ inhibition, lower the turbidity and enhance N/P ratio. ${ }^{18-20}$

Previous studies have investigated the cultivation of cyanobacterial-dominated biomass in secondary wastewater and digestate. ${ }^{21-23}$ However, to the authors' knowledge, the potential use of this biomass for recovering both phycobiliproteins and biogas has not yet been reported. Thus, this study aimed to assess the recovery of pigments (phycobiliproteins) and bioenergy (biogas) while treating wastewater using cyanobacteria-dominated biomass. To this end, the centrate (liquid part of digestate) was diluted in secondary effluent in order to provide the optimum nutrients content. $^{17,19}$ In particular, the following aspects were investigated: a) the potential of using wastewater (different dilution ratios of centrate in secondary effluent) to cultivate cyanobacteria-dominated biomass in photobioreactors (PBRs), b) the stability of biomass composition, monitoring the proportion of cyanobacteria, green microalgae and other microorganisms over time, and c) the potential biomass downstream processes for phycobiliproteins extraction followed by biogas production.

\section{MATERIALS AND METHODS}

Experimental Setup. The experimental setup consisted of cylindrical photobioreactors made of polymethacrylate, with an inner diameter of $11 \mathrm{~cm}$ and a total volume of $3 \mathrm{~L}$ (working volume of $2 \mathrm{~L}$ ). Illumination was provided by cool-white fluorescent lamps (Biolux, Osram, Germany) with a light:dark cycle of 12:12 h, with an average intensity of $150 \mu \mathrm{mol} / \mathrm{m}^{2}$ s. A water jacket around the reactors kept the temperature at $22 \pm 2{ }^{\circ} \mathrm{C}$. The photobioreactors were continuously mixed with magnetic stirrers (AGE, Velp, Italy) at $200 \mathrm{rpm}$ and aerated with $2 \mathrm{~L}$ air/min $\mathrm{pH}$ was continuously monitored with a $\mathrm{pH}$ sensor (HI1001, HANNA, U.S.A.) and maintained at 7.5 with a $\mathrm{pH}$ controller (HI 8711, HANNA, U.S.A.) by the automated addition of $0.1 \mathrm{M} \mathrm{HCl}$ or $0.1 \mathrm{M} \mathrm{NaOH}$ when needed.

Culture Conditions. Initially, one photobioreactor was inoculated with dry colonies collected from soil crusts, mostly formed by cyanobacteria (approximately 70\%, with Nostoc, Phormidium, and Geitlerinema being the most abundant genera, followed by Chroococcus, Aphanocapsa, Gloeocapsa, and Calothrix). This microbial consortium was cultivated in BG-11 10 medium (CCAP, U.K.) for 20 days, before the biomass was used to inoculate the three experimental photobioreactors. Similar studies also used consortium of microalgae dominated by cyanobacteria for further biomass valorization. $^{11,22-24}$

The three photobioreactors were then inoculated with the biomass and fed with different mixtures of secondary effluent obtained from a system of high rate algal ponds (HRAP) treating urban wastewater (for details refer to Arashiro et al. $^{25}$ ) and centrate (liquid part of digestate) from a microalgae anaerobic digestion unit. The effluent from the HRAP was filtered through $1.0 \mu \mathrm{m}$ glass microfiber filters (GF6 Whatman, GE, Germany) to avoid any possible grazer contamination. The digestate was obtained from the anaerobic digester (working volume $400 \mathrm{~L}$, HRT 20 days) of a demo scale plant using photobioreactors to treat agricultural runoff. ${ }^{26}$ The digestate was centrifuged $(4200 \mathrm{rpm}, 10 \mathrm{~min})$ and the supernatant (centrate) was mixed with the secondary effluent from the HRAP to feed the photobioreactors. Physicochemical characteristics of the secondary effluent, centrate, and digestate used in this experiment are presented in the Supporting Information (Table S1). The medium of each PBR was prepared with the following dilutions of centrate in the secondary effluent at volume proportions: PBR- $0 \%$ with only secondary effluent, PBR-15\% with centrate ( $15 \%$ volume) diluted in secondary effluent, and PBR-25\% with centrate (25\% volume) diluted in secondary effluent. Photobioreactors were operated at a hydraulic retention time (HRT) of 10 days during 45 days, with the following average nutrients loading rates: PBR- $0 \%$ at $0.93 \pm 0.17 \mathrm{mg}$ $\mathrm{N} / \mathrm{Ld}$ and $0.08 \pm 0.01 \mathrm{mg} \mathrm{P} / \mathrm{Ld}, \mathrm{PBR}-15 \%$ at $3.3 \pm 0.3 \mathrm{mg} \mathrm{N} / \mathrm{Ld}$ 
Table 1. Average Concentrations of the Main Water Quality Parameters Measured in the Influent and Effluent of PBR-0\% (Only Secondary Effluent), PBR-15\% (15\% of Centrate in Secondary Effluent), and PBR-25\% (25\% of Centrate in Secondary Effluent)

\begin{tabular}{|c|c|c|c|c|c|c|}
\hline & \multicolumn{2}{|c|}{ PBR-0\% } & \multicolumn{2}{|c|}{ PBR-15\% } & \multicolumn{2}{|c|}{ PBR-25\% } \\
\hline & influent & effluent & influent & effluent & influent & effluent \\
\hline $\operatorname{TSS}^{c}(\mathrm{mg} / \mathrm{L})$ & $<10^{a}$ & $140 \pm 98^{b}$ & $17 \pm 7^{a}$ & $214 \pm 108^{b}$ & $25 \pm 13^{a}$ & $175 \pm 60^{b}$ \\
\hline $\operatorname{VSS}^{c}(\mathrm{mg} / \mathrm{L})$ & $<10^{a}$ & $132 \pm 87^{b}$ & $16 \pm 6^{a}$ & $197 \pm 95^{b}$ & $23 \pm 11^{a}$ & $164 \pm 55^{b}$ \\
\hline $\operatorname{COD}^{c}(\mathrm{mg} / \mathrm{L})$ & & $299 \pm 168$ & $171 \pm 48^{a}$ & $374 \pm 154^{b}$ & $211 \pm 49^{a}$ & $313 \pm 73^{b}$ \\
\hline $\mathrm{sCOD}(\mathrm{mg} / \mathrm{L})$ & $59 \pm 16$ & $48 \pm 19$ & $101 \pm 22^{a}$ & $79 \pm 34^{b}$ & $148 \pm 42^{a}$ & $97 \pm 52^{b}$ \\
\hline $\mathrm{NH}_{4}{ }^{+}-\mathrm{N}(\mathrm{mg} / \mathrm{L})$ & $0.6 \pm 0.3^{a}$ & $0.12 \pm 0.11^{b}$ & $24.8 \pm 3.0^{a}$ & $3.2 \pm 3.6^{b}$ & $49.0 \pm 5.8^{a}$ & $14.4 \pm 9.3^{b}$ \\
\hline $\mathrm{NO}_{3}{ }^{-}-\mathrm{N}(\mathrm{mg} / \mathrm{L})$ & $6.0 \pm 1.6^{a}$ & $3.9 \pm 2.1^{b}$ & $5.4 \pm 1.5^{a}$ & $12 \pm 7^{b}$ & $4.7 \pm 1.4$ & $14.8 \pm 14.5$ \\
\hline $\mathrm{NO}_{2}{ }^{-}-\mathrm{N}(\mathrm{mg} / \mathrm{L})$ & $0.5 \pm 1.1$ & $0.3 \pm 1.0$ & $0.2 \pm 0.8$ & $2.9 \pm 4.7$ & $0.2 \pm 0.7^{a}$ & $5.7 \pm 6.8^{b}$ \\
\hline $\mathrm{TN}(\mathrm{mg} / \mathrm{L})$ & $10.4 \pm 1.5$ & $9.9 \pm 5.6$ & $46 \pm 4$ & $42 \pm 3$ & $81 \pm 3$ & $71 \pm 10$ \\
\hline $\mathrm{TP}^{c}(\mathrm{mg} / \mathrm{L})$ & $1.2 \pm 0.8$ & $2.8 \pm 3.3$ & $1.7 \pm 0.8$ & $3.8 \pm 3.7$ & $2.6 \pm 1.6$ & $3.4 \pm 2.9$ \\
\hline $\mathrm{PO}_{4}{ }^{3-}-\mathrm{P}(\mathrm{mg} / \mathrm{L})$ & $0.4 \pm 1.2$ & $<\mathrm{LOD}^{d}$ & $0.6 \pm 1.5$ & $<\mathrm{LOD}^{d}$ & $0.62 \pm 1.49$ & $<\mathrm{LOD}^{d}$ \\
\hline $\mathrm{TIC}(\mathrm{mg} / \mathrm{L})$ & $33 \pm 5^{a}$ & $3.2 \pm 0.8^{b}$ & $68 \pm 2^{a}$ & $3.1 \pm 4.0^{b}$ & $97 \pm 1^{a}$ & $2.9 \pm 2.0^{b}$ \\
\hline $\mathrm{TC}(\mathrm{mg} / \mathrm{L})$ & $49 \pm 3^{a}$ & $74 \pm 33^{b}$ & $97 \pm 7$ & $98 \pm 15$ & $146 \pm 9$ & $119 \pm 35$ \\
\hline
\end{tabular}

${ }^{a, b}$ Letters indicate a significant difference $(\alpha=0.05)$ between influent and effluent concentrations after Tukey test. ${ }^{c}$ Effluent concentrations measured in the mixed liquor. ${ }^{d}$ LOD: limit of detection.

and $0.17 \pm 0.08 \mathrm{mg} \mathrm{P} / \mathrm{Ld}$, and PBR-25\% at $5.7 \pm 0.6 \mathrm{mg} \mathrm{N} / \mathrm{Ld}$ and $0.26 \pm 0.16 \mathrm{mg} \mathrm{P} / \mathrm{Ld}$. The experimental setup is shown in Figure 1 .

Biomass Composition. Samples from the three photobioreactors were observed under bright field (BA310, Motic, China) and fluorescent microscopy (Eclipse E200, Nikon, Japan) weekly to characterize the communities and record their relative abundance. Biomass flocs were dissociated by homogenizing the sample for 1 min at $10000 \mathrm{rpm}$ (Polytron PT 2500 E Homogenizer, Kinematica, U.S.A.). Cell counts were performed fortnightly, with $25 \mu \mathrm{L}$ of homogenized sample, at $40 \times$ and alternating bright field and fluorescence microscopy with an excitation filter $(510-560 \mathrm{~nm})$, emission filter $(590 \mathrm{~nm})$, and dichroic beam splitter $(575 \mathrm{~nm})$ following the microscopic area counting protocol proposed by Arias et al. ${ }^{27}$ and Guillard and Sieracki. ${ }^{28} \mathrm{~A}$ detailed description of the method used for cell counting can be found in the Supporting Information file. The identification of microbial genera was based both on conventional taxonomic books ${ }^{29,30}$ and three online databases: NCBI Taxonomy Browser, AlgaeBase, and the CyanoDB.cz.

Phycobiliproteins Extraction. Phycobiliproteins (phycocyanin and phycoerythrin) content from the biomass of each photobioreactor was quantified. Aliquots taken daily were centrifuged (4200 rpm, $10 \mathrm{~min}$ ) and biomass was rinsed twice with distilled water and frozen $\left(-21{ }^{\circ} \mathrm{C}\right)$ until further use. ${ }^{31}$ Microbial cells disruption was done by repeating 3 freeze-thaw cycles $(-21$ to +4 ${ }^{\circ} \mathrm{C}$ in darkness). ${ }^{31,32}$ The biomass paste was then used for determining the dry weight (DW) and phycobiliproteins content. The DW content was measured according to Standard Methods $\left(2540 \mathrm{~B}\right.$ - Total Solids Dried at $\left.103-105{ }^{\circ} \mathrm{C}\right),{ }^{33}$ by weighing approximately $0.5 \mathrm{~g}$ of biomass paste in an analytical balance (readability: $0.0001 \mathrm{~g}$ ). Extraction of these compounds was done by adding $250 \mathrm{mg}$ of the biomass paste into $15 \mathrm{~mL}$ covered vessels with sodium phosphate buffer at $\mathrm{pH} 7$ as the solvent at a proportion 1:10 (w:w, biomass:solvent). ${ }^{32,34}$ Mixtures were then submitted to 5 ultrasonic cycles at $20 \mathrm{kHz}$ of $1 \mathrm{~min}$ each (Qsonica S-4000, U.S.A.) in ice bath to avoid overheating. ${ }^{31,32,35}$ The resulting slurry was centrifuged at $10000 \mathrm{rpm}$ for $15 \mathrm{~min}$ at $4{ }^{\circ} \mathrm{C}$ (LegendMicro21, ThermoScientific, U.S.A.) to remove cell debris. The precipitate was stored for further use and the supernatant was collected and measured in a spectrophotometer at 280, 562, and $620 \mathrm{~nm}$, to quantify the amount of phycocyanin and phycoerythrin according to Bennett and Bogobad. ${ }^{36}$ Purity was determined as the absorbance ratios of $A_{620} / A_{280}$ for phycocyanin and $A_{562} / A_{280}$ for phycoerythrin. ${ }^{5}$ All of the analyses were done in triplicate and results are given as average values.
Biochemical Methane Potential Test. Biochemical methane potential (BMP) tests were carried out to assess the potential to recover biogas after the phycobiliproteins extraction process. BMP tests were performed in serum bottles of $160 \mathrm{~mL}$ filled up to $50 \mathrm{~mL}$ of liquid volume with certain amounts of inoculum and substrate, corresponding to $5 \mathrm{~g}$ of volatile solids (VS) substrate/L and a substrate to inoculum ratio (S/I) of $0.5 \mathrm{~g}$ of VS substrate/g VS inoculum. The inoculum was obtained from the digester sludge at a wastewater treatment plant from Barcelona Metropolitan Area and used immediately after the sample was collected. The substrates evaluated were the biomass grown in the three photobioreactors, before and after phycobiliproteins extraction. Each trial was performed in triplicate.

The bottles were flushed with helium gas, sealed with butyl rubber stoppers and placed in a platform shaker incubator (OPAQ Ovan, Spain) at $35^{\circ} \mathrm{C}$ and $80 \mathrm{rpm}$. Pressure in each bottle was periodically measured with a digital manometer (GMH 3151 Greisinger, Germany) and biogas production was calculated by subtracting the blank (inoculum only) production. Measurements were done until the daily methane production was less than $1 \%$ of the total accumulated methane production in all bottles. Methane content in biogas was analyzed by gas chromatography (Trace GC Thermo Finnigan, U.S.A.), following the procedure described by Solé-Bundó et al.. ${ }^{3}$

The calculation of anaerobic biodegradability of each substrate was based on the net methane production $\left(\mathrm{mL} \mathrm{CH}_{4}\right)$ and the theoretical methane yield under standard conditions, $350 \mathrm{~mL}$ of $\mathrm{CH}_{4}$ for each gram of degraded COD. ${ }^{38}$

Analytical Methods. The wastewater treatment efficiency and biomass production in the photobioreactors was evaluated by monitoring the following parameters. Total suspended solids (TSS), volatile suspended solids (VSS), chlorophyll-a, and total and soluble chemical oxygen demand (COD and sCOD) were measured according to Standard Methods. ${ }^{33} \mathrm{NH}_{4}^{+}-\mathrm{N}$ was measured following Solórzano, ${ }^{39}$ and $\mathrm{NO}_{2}{ }^{-}-\mathrm{N}, \mathrm{NO}_{3}{ }^{-}-\mathrm{N}$, and $\mathrm{PO}_{4}{ }^{3-}-\mathrm{P}$ through isocratic mode with carbonate-based eluents at a temperature of 30 ${ }^{\circ} \mathrm{C}$ and a flow of $1 \mathrm{~mL} / \mathrm{min}$ (ICS-1000, Dionex Corporation, U.S.A.; limits of detection (LOD) were $0.9 \mathrm{mg} / \mathrm{L}$ of $\mathrm{NO}_{2}{ }^{-}-\mathrm{N}, 1.12$ of $\mathrm{NO}_{3}{ }^{-}$$\mathrm{N}$, and $0.8 \mathrm{mg} / \mathrm{L}$ of $\left.\mathrm{PO}_{4}{ }^{3-}-\mathrm{P}\right)$. Total carbon (TC), total inorganic carbon (TIC), and total nitrogen (TN) were analyzed with a multi N/C 2100S, Analytik Jena, Germany. For the BMP test, total solids (TS) and volatile solids (VS) were measured according to Standard Methods. ${ }^{33}$ All of the analyses were done in triplicate and results are given as average values.

Statistical and Model-Based Analyses. Experimental data regarding wastewater treatment efficiency, phycobiliproteins content 
PBR-0\%
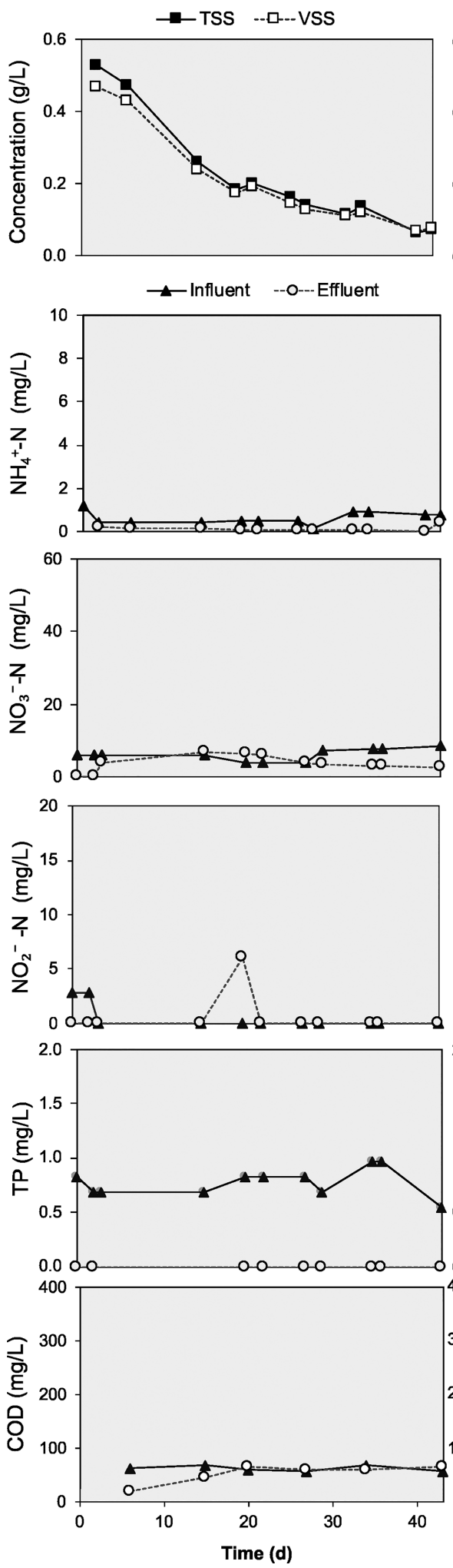

Figure 2. Average total suspended solids (TSS; concentrations of $\mathrm{NH}_{4}^{+}-\mathrm{N}, \mathrm{NO}_{3}^{-}-\mathrm{N}, \mathrm{NO}_{2}^{-}-\mathrm{N}$, total phosphorus (TP), and chemical oxygen demand (COD) measured in PBR-0\% (only secondary effluent), PBR-15\% (15\% of centrate in secondary effluent), and PBR-25\% (25\% of centrate in secondary effluent).

and biochemical methane potential were statistically assessed via multifactor analysis of variance (ANOVA; $\alpha=0.05$ ). The Tukey test $(\alpha=0.05)$ was used as a posthoc test using Minitab 18 (Minitab Inc., PA, U.S.A.).
PBR-15\%

PBR-25\%
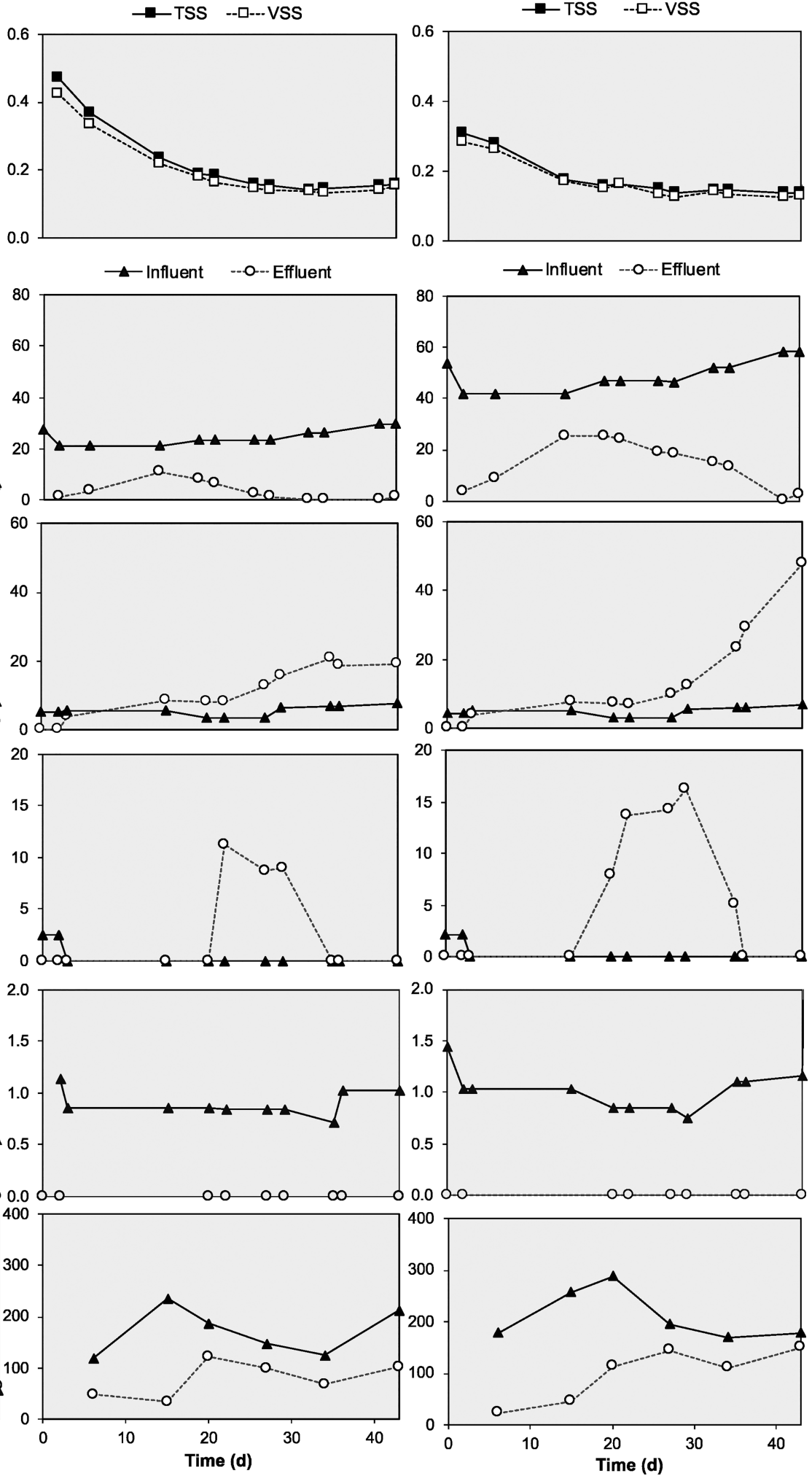
Table 2. Average Removal Efficiencies and Rates of the Main Wastewater Parameters Observed in PBR-0\% (Only Secondary Effluent), PBR-15\% (15\% of Centrate in Secondary Effluent), and PBR-25\% (25\% of Centrate in Secondary Effluent)

\begin{tabular}{|c|c|c|c|c|c|c|}
\hline & \multicolumn{3}{|c|}{ removal efficiencies (\%) } & \multicolumn{3}{|c|}{ removal rates $(\mathrm{mg} / \mathrm{Ld})$} \\
\hline & PBR-0\% & PBR-15\% & PBR-25\% & PBR-0\% & PBR-15\% & PBR-25\% \\
\hline $\mathrm{NH}_{4}^{+}-\mathrm{N}$ & $82 \pm 46$ & $86 \pm 12$ & $71 \pm 12$ & $0.53 \pm 0.41$ & $22 \pm 7$ & $35 \pm 15$ \\
\hline $\mathrm{NO}_{3}{ }^{-}-\mathrm{N}$ & $36 \pm 26^{a}$ & $-114 \pm 89^{b}$ & $-212 \pm 128^{b}$ & $2.17 \pm 0.80$ & $-6.17 \pm 0.89$ & $-10.0 \pm 1.3$ \\
\hline $\mathrm{NO}_{2}{ }^{-}-\mathrm{N}$ & $37 \pm 222^{a}$ & $-1083 \pm 191^{a, b}$ & $-2630 \pm 316^{b}$ & $0.19 \pm 5.39$ & $-2.64 \pm 4.79$ & $-14.6 \pm 4.4$ \\
\hline total $\mathrm{NO}_{x}-\mathrm{N}$ & $36 \pm 249^{a}$ & $-156 \pm 280^{b}$ & $-314 \pm 444^{b}$ & $2.4 \pm 6.2$ & $-8.8 \pm 5.7$ & $-24.6 \pm 5.6$ \\
\hline TIN & $40 \pm 98$ & $40 \pm 50$ & $32 \pm 70$ & $3.0 \pm 5.1$ & $14.0 \pm 7.5$ & $20.6 \pm 12.9$ \\
\hline $\mathrm{TN}$ & $4.0 \pm 14.8$ & $9 \pm 14$ & $13 \pm 17$ & $2.9 \pm 6.6$ & $12.8 \pm 5.8$ & $10.0 \pm 5.7$ \\
\hline $\mathrm{TP}^{c}$ & $100 \pm 1$ & $100 \pm 0$ & $100 \pm 0$ & $0.10 \pm 1.58$ & $0.23 \pm 1.49$ & $0.36 \pm 1.48$ \\
\hline TIC & $90 \pm 35^{a}$ & $94 \pm 4^{a, b}$ & $98 \pm 75^{b}$ & $29 \pm 5$ & $64 \pm 8$ & $95 \pm 3$ \\
\hline $\operatorname{COD}^{c}$ & $30 \pm 22$ & $52 \pm 20$ & $51 \pm 30$ & $12 \pm 21$ & $92 \pm 58$ & $114 \pm 76$ \\
\hline
\end{tabular}

${ }^{a, b}$ Letters indicate a significant difference $(\alpha=0.05)$ of removal efficiencies between PBRs after Tukey test. ${ }^{c}$ Effluent concentrations used to calculate TP and COD removal efficiencies were measured from filtered samples (soluble concentrations).

$$
P=P_{0}[1-\exp (-k t)]
$$

where $P_{0}$ stands for the methane production potential $\left(\mathrm{mL} \mathrm{CH}_{4} / \mathrm{g}\right.$ VS), $k$ is the first order kinetic rate constant $\left(\right.$ day $\left.^{-1}\right), P$ is the accumulated methane production at time $t\left(\mathrm{~mL} \mathrm{CH}_{4} / \mathrm{g} \mathrm{VS}\right)$, and $t$ is time (day).

The error variance $\left(s^{2}\right)$ of modeled methane production from eq 1 based on the actual methane production was estimated by the following eq (eq 2):

$$
s^{2}=\frac{\sum(y-x)}{N-K}
$$

where $y$ is the experimental value, $x$ is the value estimated by the model, $N$ is the number of samples $(N=15)$, and $K$ is the number of model parameters $(K=2)$.

The coefficient of determination $R^{2}$ between the modeled and the actual methane production was calculated by the eq 3 .

$$
R^{2}=1-\frac{\sum(y-x)^{2}}{\sum(y-\bar{y})^{2}}
$$

where $\bar{y}$ is the average experimental value.

\section{RESULTS AND DISCUSSION}

Wastewater Treatment and Biomass Growth. Average concentrations of water quality parameters in the influent and mixed liquor of each photobioreactor are shown in Table 1 . Variations in concentrations of influent and effluent of each photobioreactor are illustrated in Figure 2.

Average concentration of $\mathrm{NH}_{4}^{+}-\mathrm{N}$ in the secondary effluent throughout the experimental period was very low (Table 1 ), thus PBR-0\% reached a high removal efficiency of $82 \%$. For PBR-15\% and PBR-25\%, influent $\mathrm{NH}_{4}{ }^{+} \mathrm{N}$ was higher due to centrate addition (Table 1). Nevertheless, high average removal efficiencies were also reached in PBR-15\% and PBR $25 \%$ (87 and $71 \%$, respectively) upon steady state (approximately 22 days for PBR-15\% and 36 days for PBR$25 \%$; Figure 2). Indeed, there was no significant difference between $\mathrm{NH}_{4}{ }^{+}-\mathrm{N}$ removal efficiencies in all photobioreactors (Table 2). Concentrations of $\mathrm{NO}_{3}{ }^{-}-\mathrm{N}$ and $\mathrm{NO}_{2}{ }^{-}-\mathrm{N}$ were also very low in the secondary effluent, so PBR- $0 \%$ could reach average removal efficiency of $36 \%$ and $37 \%$, respectively. However, for PBR-15\% and PBR-25\%, production of $\mathrm{NO}_{2}{ }^{-}-\mathrm{N}$ during the first 30 days and accumulation of $\mathrm{NO}_{3}^{-}-\mathrm{N}$ concentrations were observed (Figure 2). Accumulation in PBR-25\% was significantly higher than in PBR-0\% and PBR$15 \%$, due to the higher $\mathrm{NH}_{4}{ }^{+}-\mathrm{N}$ concentrations in the influent, by 76 -fold compared to PBR- $0 \%$ and 2 -fold compared to
PBR-15\%. These variations of $\mathrm{NO}_{3}{ }^{-}-\mathrm{N}$ and $\mathrm{NO}_{2}{ }^{-}-\mathrm{N}$ concentrations in all reactors suggest nitrification activity in these systems. Arias et al. ${ }^{23}$ also reported nitrification process in a photobioreactor treating secondary effluent and digestate.

Regarding total phosphorus, all photobioreactors showed very high removal efficiencies (Table 2) and its absence in the effluent suggests that this nutrient might have been a limiting factor for the growth of microorganisms in all reactors. COD removal efficiencies ranged from 30 to $52 \%$ and photobioreactors did not perform significantly different (Table 2). In addition, during the experimental period, COD concentrations in photobioreactors effluents were below the discharge limit of $125 \mathrm{mg} \mathrm{O} / \mathrm{L}^{41}$ Other studies treating centrate have also reported high removal efficiencies of nutrients and COD. ${ }^{17,19}$

Variations of TSS and VSS in the photobioreactors showed a decrease during the first 20 days before reaching the steady state (Figure 2). The effluent of PBR-0\%, PBR-15\%, and PBR$25 \%$ had very low concentrations of inorganic soluble phosphate and inorganic carbon (Table 1) due to high removal efficiencies (Table 2). Despite the constant air supply in the photobioreactors, inorganic carbon reached limiting levels, which supported the assumption of nitrification process in the systems. ${ }^{42} \mathrm{Ge}$ et al. carried out similar experiments treating centrate diluted in secondary wastewater reporting also a relatively low centrate loading rate applied (10\% diluted centrate by volume), which may have consequently limited the biomass productivity due to low phosphorus availability (influent concentration between 1.3 to $1.8 \mathrm{mg} \mathrm{PO}_{4}{ }^{3-}-\mathrm{P} / \mathrm{L}$ ).

In general, ammonium is the preferential form of nitrogen uptake for most microalgae and cyanobacteria species, followed by nitrate. ${ }^{43}$ This is in accordance with the results obtained in this study, in which ammonium removal was very high (up to $86 \%$ ), due to biomass uptake and nitrification processes. Nitrate accumulation was also observed. Based on that, it is assumed that microalgal growth was limited not only by the low availability of phosphorus and inorganic carbon, as mentioned previously, but also by competition with bacterial processes. Praveen et al. ${ }^{18}$ carried out a study in which a microalgal-bacterial consortium was cultivated in synthetic wastewater mixed with anaerobic digestate, reaching $99.8 \%$ decrease in $\mathrm{NH}_{4}{ }^{+} \mathrm{N}$ concentrations with high accumulation of $\mathrm{NO}_{3}{ }^{-}-\mathrm{N}$, also indicating presence of nitrifying bacteria. Moreover, the limitation in inorganic carbon has been related to nitrification processes and highlighted the fact that more unfavorable conditions occur in microalgae-based processes 

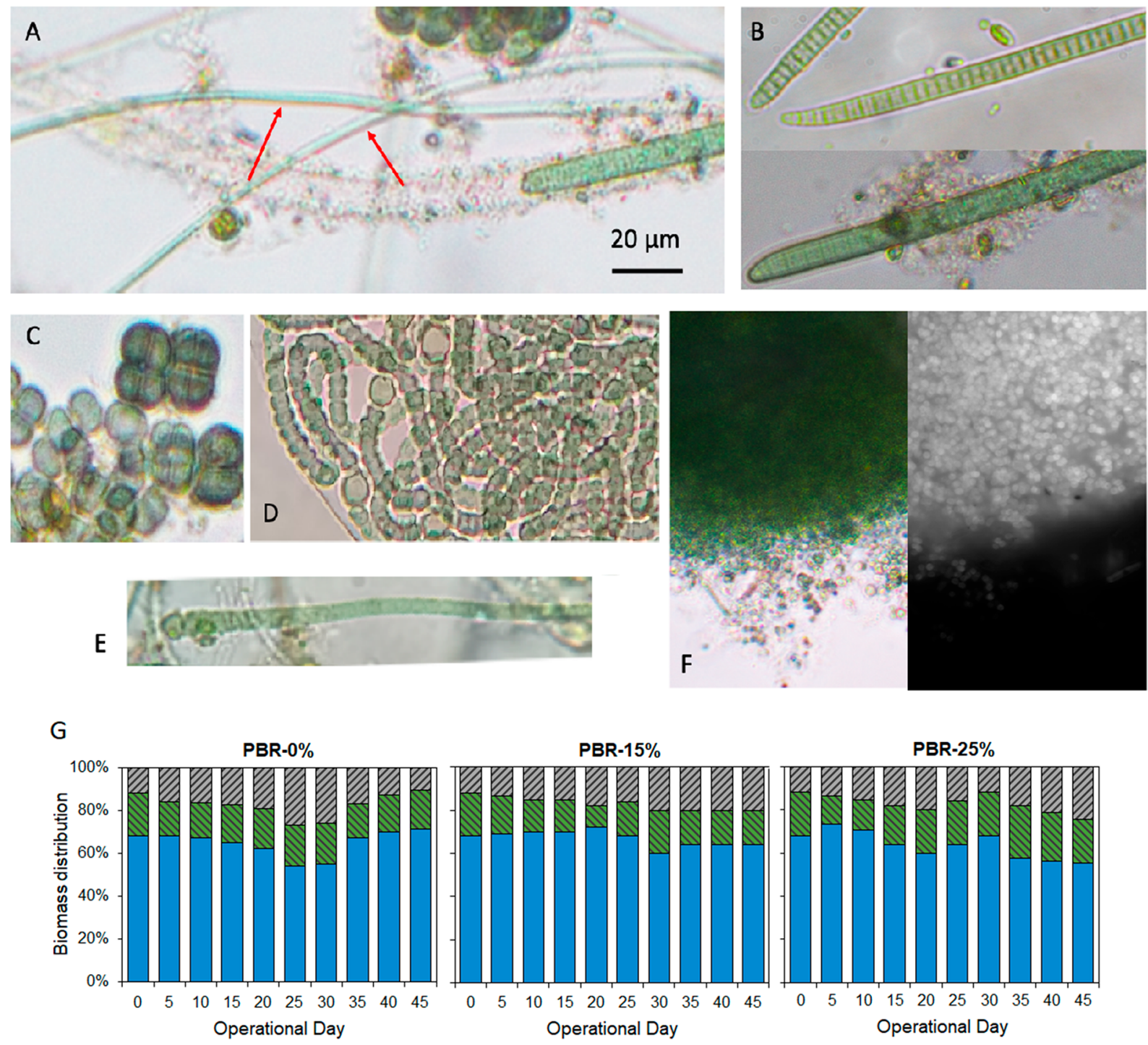

๑ Cyanobacteria $₫$ Microalgae $\square$ Others

Figure 3. Images of biomass grown in the three photobioreactors, taken throughout the entire experimental period using a brightfield and fluorescence microscope. A, Geitlerinema sp.; B, Phormidium sp.; C, Chroococcus sp.; D, Nostoc sp.; E, Calothrix sp.; F, Aphanocapsa sp. under light and fluorescence (scale applies to all images); G, Evolution of the biomass composition in PBR-0\% (only secondary effluent), PBR-15\% (15\% of centrate in secondary effluent), and PBR-25\% (25\% of centrate in secondary effluent).

since both photosynthetic autotrophs and nitrifying bacteria compete for the same inorganic carbon sources. ${ }^{42}$ Likewise, the accumulation of nitrate and the decrease in $\mathrm{TN}$ concentrations (Table 1), indicate that denitrification might have occurred in PBR-15\% and PBR-25\%, which would be achieved where dissolved oxygen concentration gradients resulted in anoxic zones within algal-bacterial flocs. ${ }^{42}$ Nevertheless, considering cases in which carbon sources from other waste streams (e.g., flue gas) could be combined with a mixture of centrate and secondary effluent, high nutrients removal efficiencies could be achieved and possibly implemented at full-scale. ${ }^{44}$

Biomass Composition. The microorganisms observed in each sample were grouped within three main categories: cyanobacteria, microalgae and "others". The latter included any microorganism which did not classify as either of the other two categories, such as diatoms and grazers (rotifers, amoebas, ciliates, and flagellates). ${ }^{45}$ Cyanobacteria remained the dominant clade in the three photobioreactors throughout the entire experimental period for PBR-0\%, PBR-15\%, and PBR-25\%, ranging from a minimum of 55,65 , and $55 \%$ to a maximum of 80,72 , and $73 \%$ respectively (Figure $3, \mathrm{G}$ ). These results support the studies performed by Arias et al., ${ }^{23,27}$ where cyanobacterial cocultures were used to treat secondary effluents, highlighting the relevance of cyanobacteria's dual-role of treating wastewater and producing valuable products. $^{46}$ Average abundance of cyanobacteria in the biomass grown in PBR-0\% $(60 \pm 6 \%)$ was significantly lower than in PBR-15\% (68 $\pm 4 \%$, p-value $\left.=3.1 \times 10^{-5}\right)$ and PBR-25\% (65 $\pm 5 \%$, p-value $=0.033)$, while there was no significant difference between the last two ( $p$-value $=0.089)$. This indicates that the addition of centrate in secondary effluent provided better conditions for cyanobacteria.

Similar to PBR-0\%, the biomass from PBR-15\% and PBR$25 \%$ formed flocs held together by filamentous cyanobacteria with a distinct deep blue-green color. The taxonomical 
a)

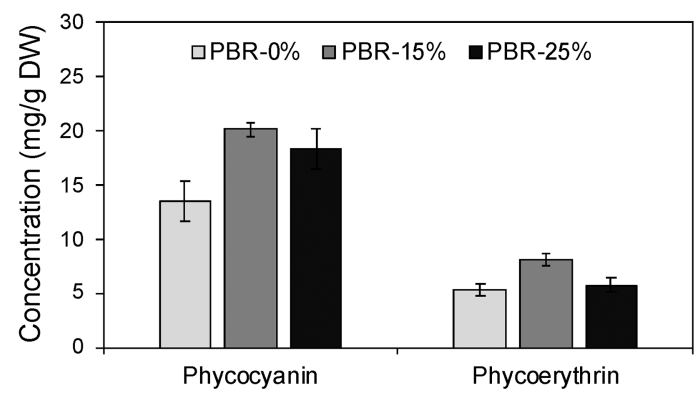

c)

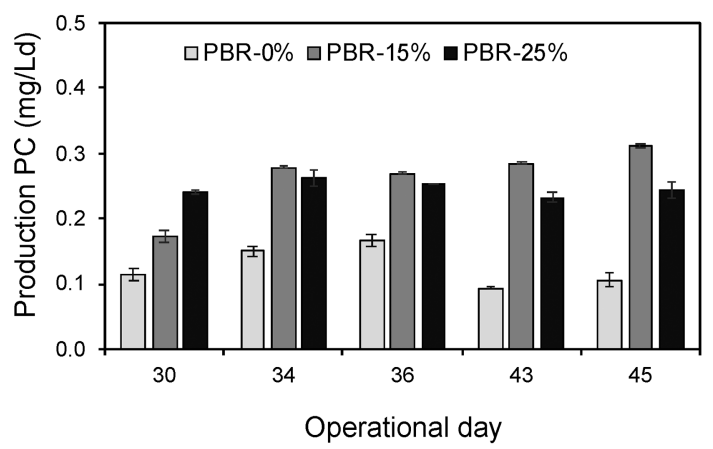

b)

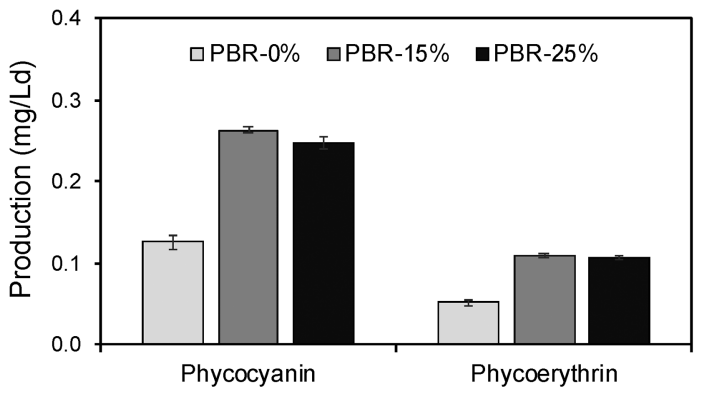

d)

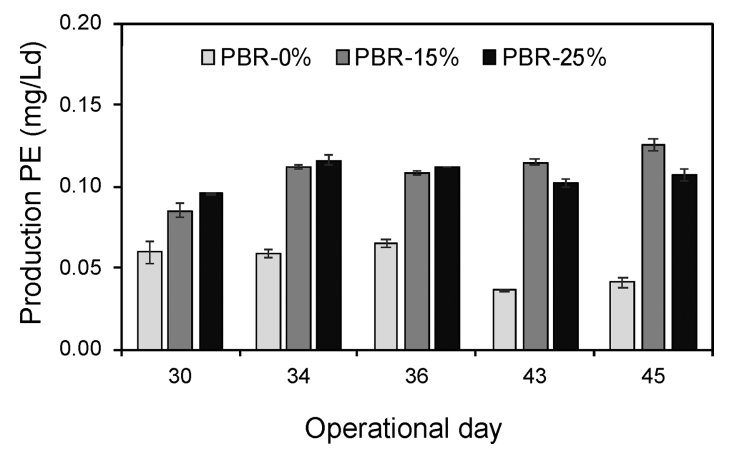

Figure 4. Overall average phycocyanin and phycoerythrin (a) concentrations (mg/g DW) and (b) production rates (mg/Ld); production rates of (c) phycocyanin and (d) phycoerythrin extracted from biomass grown in PBR-0\% (only secondary effluent), PBR-15\% (15\% of centrate in secondary effluent), and PBR-25\% (25\% of centrate in secondary effluent).

composition of the biomass showed the Nostocales, Chroococales, and Oscillatoriales orders as the main cyanobacterial fraction. Within these, the following 7 genera were distinguished: Nostoc, Calothrix, Aphanocapsa, Gloeocapsa, Chroococcus, Geitlerinema, and Phormidium (Figure 3A-F). All genera grew and remained in equal proportions throughout the experimental period.

Phycobiliproteins Extraction. The biomass used for the quantification of phycobiliproteins was harvested and accumulated during the experimental period, but only the results of the last 15 days (days 30-45) are shown in this section, as this was the period in which the photobioreactors were more stable. Cyanobacterial phycocyanin and phycoerythrin were detected in all photobioreactors. This was confirmed by analyzing the absorbance peaks observed at $620 \mathrm{~nm}$ and at $562 \mathrm{~nm}$, which are typical for cyanobacterial phycocyanin and phycoerythrin, respectively. ${ }^{47}$ The average phycocyanin concentrations measured in biomass grown in PBR-0\%, PBR-15\% and PBR-25\% were $13.5 \pm 1.8,20.1 \pm 0.6$, and $18.3 \pm 1.9 \mathrm{mg}$ phycocyanin/g DW (Figure 4a). Although PBR-0\% had lower content of phycocyanin than PBR-15\% and PBR-25\%, these concentrations were not significantly different $(p$-value $=0.054)$. The higher concentrations in PBR-15\% and PBR-25\% are in accordance with the abundance of cyanobacteria, which was significantly higher in these PBRs compared to PBR- $0 \%$. Regarding phycoerythrin, the average concentrations measured in biomass grown in PBR-0\%, PBR$15 \%$, and PBR-25\% were $5.3 \pm 0.5,8.1 \pm 0.5$, and $5.7 \pm 0.7$ mg phycoerythrin/g DW (Figure 4a). Similarly to phycocyanin content, PBR- $0 \%$ had the lowest concentration of phycoerythrin, which was significantly lower than PBR-15\% ( $\mathrm{p}$-value $=0.017)$, while there was no difference neither between PBR-0\% and PBR-25\% (p-value = 0.605) nor between PBR-15\% and PBR-25\% ( $p$-value $=0.055)$.
Considering the biomass concentration in each photobioreactor, the overall average production rates of phycobiliproteins were calculated (Figure $4 b$ ) and the progression of the production rates of phycocyanin (Figure 4c) and phycoerythrin (Figure 4d) over time in each photobioreactor were estimated. The production rates of phycocyanin and phycoerythrin in PBR-0\% were significantly lower than in PBR-15\% (p-values $=1.0 \times 10^{-3}$ and $1.8 \times 10^{-4}$, respectively) and PBR-25\% (p-values $=3.8 \times 10^{-5}$ and $3.6 \times 10^{-5}$, respectively), while no difference was found between PBR$15 \%$ and PBR-25\% (p-values $=0.507$ and 0.739 , respectively). This is in accordance with the limiting concentrations of nutrients in all reactors, especially in PBR-0\%, mentioned previously.

Phycobiliproteins must be purified in order to meet the specific standards of diverse applications. Purity is usually determined as the absorbance ratios of $A_{620} / A_{280}$ for phycocyanin and $A_{562} / \mathrm{A}_{280}$ for phycoerythrin, which define the relationship between the presence of the specific phycobiliprotein and other contaminating proteins. ${ }^{5}$ A purity ratio $\geq 0.7$ refers to food grade pigment, while reagent and analytical grade correspond to $\geq 3.9$ and $\geq 4.0$, respectively. ${ }^{48}$ In this study, average purity ratios of phycocyanin extracted from biomass grown in PBR-0\%, PBR-15\%, and PBR-25\% were $2.7 \pm 0.4,2.1 \pm 0.1$, and $3.0 \pm 0.3$, which were not significantly different $(\mathrm{p}$-value $=0.123)$. Likewise, average purity ratios of phycoerythrin extracted from biomass grown in PBR-0\%, PBR-15\%, and PBR-25\% were $2.1 \pm 0.2,1.6 \pm$ 0.1 , and $2.2 \pm 0.2$, also not significantly different ( $\mathrm{p}$-value $=$ 0.129). However, although purity ratios of phycocyanin are higher than the food grade standard, the fact that this biomass was cultivated in wastewater might hinder the application of the extracted pigment for this purpose. Therefore, the most suitable option would be to further purify the phycobilipro- 


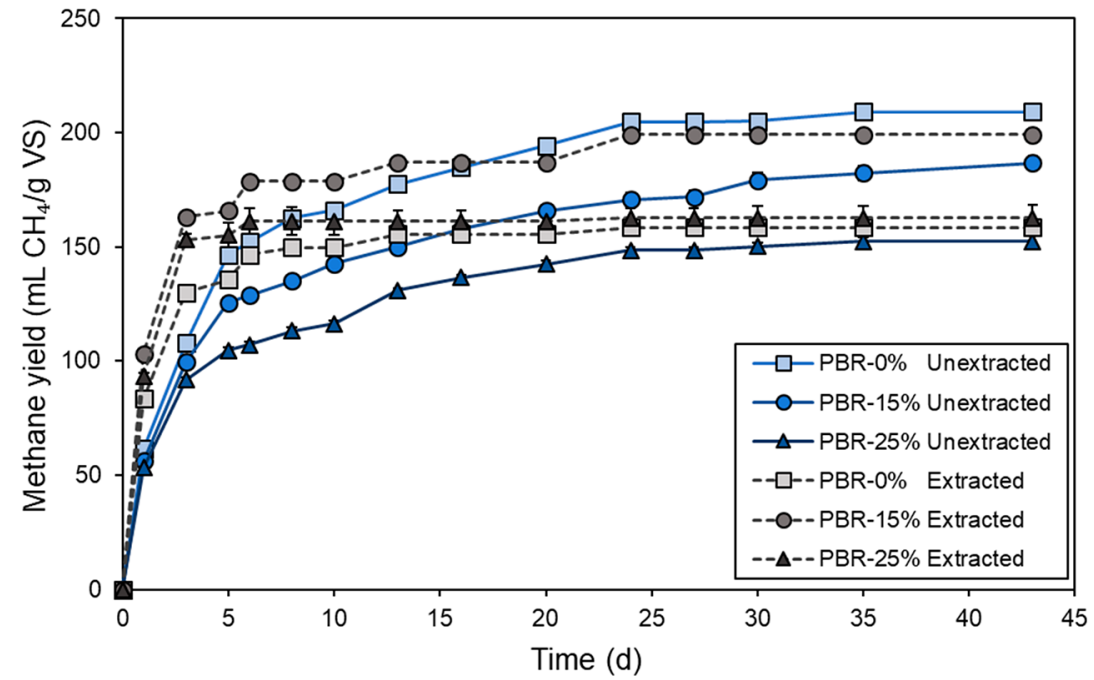

Figure 5. Cumulative methane yields of biomass harvested from PBR- $0 \%$ (only secondary effluent), PBR-15\% ( $15 \%$ of centrate in secondary effluent), and PBR-25\% (25\% of centrate in secondary effluent), unextracted and after extraction (extracted) of phycobiliproteins.

Table 3. Summary of the Methane Yield (Initial after 6 Days and Final after 43 Days of Incubation), Methane Content, Anaerobic Biodegradability (Mean Values \pm Standard Deviation; $n=3$ ), First-Order Kinetics Constant $(k)$ Obtained from eq $1^{c}$

\begin{tabular}{|c|c|c|c|c|c|c|}
\hline \multirow[b]{2}{*}{ substrate } & \multicolumn{2}{|c|}{ PBR-0\% } & \multicolumn{2}{|c|}{ PBR-15\% } & \multicolumn{2}{|c|}{ PBR-25\% } \\
\hline & unextracted & extracted & unextracted & extracted & unextracted & extracted \\
\hline $\begin{array}{l}\text { initial methane yield } \\
\left(\mathrm{mL} \mathrm{CH}_{4} / \mathrm{g} \text { VS }\right)\end{array}$ & $152.2 \pm 0.5^{a}$ & $146.6 \pm 1.2^{a}$ & $128.8 \pm 1.4^{a}$ & $178.8 \pm 1.0^{a}$ & $107.2 \pm 1.4^{a}$ & $161.0 \pm 5.8^{a}$ \\
\hline $\begin{array}{l}\text { final methane yield } \\
\left(\mathrm{mL} \mathrm{CH}_{4} / \mathrm{g} \text { VS }\right)\end{array}$ & $209.1 \pm 1.5^{a}$ & $158.6 \pm 3.5^{a}$ & $186.7 \pm 3.0^{a}$ & $199.2 \pm 0.2^{a}$ & $152.5 \pm 2.1^{a}$ & $162.5 \pm 5.7^{a}$ \\
\hline methane content (\%) & $71.8 \pm 0.1^{a}$ & $71.8 \pm 0.2^{a}$ & $72.4 \pm 2.7^{a}$ & $72.5 \pm 0.4^{a}$ & $72.4 \pm 1.6^{a}$ & $72.4 \pm 1.2^{a}$ \\
\hline $\begin{array}{l}\text { anaerobic } \\
\text { biodegradability (\%) }\end{array}$ & $61.8 \pm 1.6$ & $82.1 \pm 3.5$ & $78.9 \pm 3.0$ & $95.2 \pm 0.2$ & $58.6 \pm 2.1$ & $87.1 \pm 5.7$ \\
\hline $\begin{array}{l}\text { first-order kinetics } \\
\text { constant } k\left(\text { day }^{-1}\right)\end{array}$ & $\begin{array}{c}0.239^{a}\left(s^{2}=102 ;\right. \\
\left.R^{2}=0.988\right)\end{array}$ & $\begin{array}{c}0.661^{b}\left(s^{2}=32 ;\right. \\
\left.R^{2}=0.992\right)\end{array}$ & $\begin{array}{c}0.243^{a}\left(s^{2}=121 ;\right. \\
\left.R^{2}=0.981\right)\end{array}$ & $\begin{array}{c}0.683^{b}\left(s^{2}=89 ;\right. \\
\left.R^{2}=0.985\right)\end{array}$ & $\begin{array}{c}0.254^{a}\left(s^{2}=109\right. \\
\left.R^{2}=0.976\right)^{a}\end{array}$ & $\begin{array}{c}0.877^{b}\left(s^{2}=3 ;\right. \\
\left.R^{2}=0.999\right)\end{array}$ \\
\hline
\end{tabular}

${ }^{a, b}$ Letters indicate a significant difference between trials $(\alpha=0.05)$ after Tukey test. ${ }^{c}$ Error variances $s^{2}$ from eq 2 and coefficient of determination $R^{2}$ obtained from eq 3 are shown between brackets.

teins in order to reach reactive or analytical grade, increasing the market value of these bioproducts.

To date, very few studies assessing the recovery of phycobiliproteins from biomass grown in wastewaters were reported. Wood et al. $^{15}$ demonstrated the feasibility of cultivating cyanobacteria in oil and natural gas extraction wastewater with production of phycocyanin with a maximum yield of $16.9 \pm 3.4 \mathrm{mg} / \mathrm{g}$ DW and a maximum crude extract purity of $0.23 \pm 0.03$. The phycocyanin concentration was very similar, but the purity ratio found in the present study was much higher, most probably due to the different extraction techniques used. Khatoon et al. ${ }^{14}$ cultivated cyanobacteria in aquaculture wastewater and reported a much higher value of maximum phycobiliproteins $(237 \mathrm{mg} /$ g DW), yet with lower purity ratio (1.14) than the present study. The discrepancies might be related to the different species or the calculation method used in that study. Van Den Hende et al. ${ }^{11}$ investigated the potential to cultivate cyanobacteria-dominated biomass in food-industry effluent and flue gas. They reported extraction of $61.1 \mathrm{mg}$ phycocyanin/g VS with 0.43 purity ratio of crude extract, and $30.1 \mathrm{mg}$ phycoerythrin/g VS with 0.36 purity ratio. In general, when comparing with other studies, the concentrations of phycobiliproteins found in the present study were lower, but purity ratios of crude extracts were higher.
Biochemical Methane Potential. The BMP test was carried out in order to investigate the potential biogas recovery from biomass harvested in each photobioreactor, with extraction (extracted) and without the extraction (unextracted) of phycobiliproteins. The methane yield of each trial over an incubation period of 43 days is shown in Figure 5. The methane content in biogas was similar in all cases, around $72 \%$.

The lowest final methane yield $\left(152.5 \pm 2.1 \mathrm{~mL}\right.$ of $\mathrm{CH}_{4} / \mathrm{g}$ VS) was obtained from unextracted biomass of PBR-25\%, and the highest final methane yield $\left(209.1 \pm 1.5 \mathrm{~mL}\right.$ of $\mathrm{CH}_{4} / \mathrm{g}$ VS) was from unextracted biomass of PBR-0\%. Methane production of extracted biomass was mainly observed during the initial stage of the incubation (especially the first 6 days) and remained constant after that. For unextracted biomass, methane production was rapidly increased until day 15 and very little after that. Overall, there was no significant difference between the methane yield (both initial and final) of all substrates (Table 3) and the average methane yields obtained were within the range reported for microalgae BMP tests. ${ }^{49}$

However, the kinetics of extracted biomass were significantly faster $(p$-value $=0.002)$ than of unextracted biomass from all photobioreactors. As expected, this performance could be explained by the fact that extracted biomass contained more readily biodegradable material (which was 
transformed into biogas) than unextracted biomass, since extracted biomass was submitted to cell disruption. This is a matter of concern, since faster kinetics would mean lower HRT and reactor volume, and hence lower costs, upon scaleup. Indeed, PBR-15\% and PBR-25\% extracted showed the highest accumulated methane yield until the sixth day, reaching $90 \%$ and $99 \%$ of the final methane yield. Therefore, no significant difference was observed in terms of methane yields but the rate in which it was produced.

Comparing the final methane yield of extracted and unextracted biomass, for PBR-0\% unextracted biomass showed a $32 \%$ higher methane yield than extracted biomass. This might be related to the abundance of cyanobacteria compared to microalgae in PBR-0\%, which was lower than in PBR-15\% and PBR-25\%. The ultrasonic treatment was probably more effective in biomass of PBR-15\% and PBR-25\% than in PBR$0 \%$, since cyanobacterial cell walls are easier to disrupt than those of eukaryotic microalgae. Indeed, final methane yields from extracted biomass from PBR-15\% and PBR-25\% were $6.7 \%$ and $6.6 \%$ higher than unextracted biomass. This means that, by combining the extraction of pigments and the production of biogas from residual biomass, we would not only obtain high-value compounds, but also more energy, as compared to the sole production of biogas. Economically, it has already been shown that the production of bioproducts from microalgae grown in wastewater is more profitable than the generation of biogas. ${ }^{50}$

To sum up, recovery of bioenergy as methane with residual biomass after extraction of high-value products seems to be a very promising alternative to minimize the energy demand in a microalgae cultivation system. Indeed, the extraction of bioactive compounds prior to anaerobic fermentation can be considered as a pretreatment of microalgal and cyanobacterial biomass in order to increase the anaerobic biodegradability. ${ }^{51,52}$ Additionally, the application of the pigments could be focused on nonfood alternatives, such as paintings for textiles or arts. Recent studies have reported the use of extracts of red pigment from the macroalgae Gracilaria vermiculophylla and blue pigment from the Arthrospira platensis, showing even distribution on the cotton and wool fabrics, with results representing the viability and the quality of naturally dyed textiles. ${ }^{53,54}$ Although these are also early stage results, it clearly shows the drives and trends for sustainable solutions.

Although further improvements are needed in order to optimize processes involved (e.g., cultivation, extraction techniques and bioenergy recovery), the concept proposed in this study could potentially be applied to promote wastewater treatment while recovering high-value bioproducts from fresh biomass, and bioenergy from residual (extracted) biomass. By using wastewaters from different sources as cultivation medium for developing "low-value-high-volume" product and "high-value-low-volume" product, then production costs can be minimized while simultaneously remediating the wastewater. ${ }^{19,55}$ This way, biogas production would be recommended to maximize resources recovery by using the residual biomass (after extraction of high-value bioproducts), thus minimizing the energy demand, rather than a unique valorization step. ${ }^{56}$ Therefore, further research is encouraged in order to investigate the potential upscaling with a biorefinery approach, with different types of wastewater (e.g., secondary effluent from municipal, industrial wastewater or agricultural runoff, in order to analyze important aspects, such as $\mathrm{C} / \mathrm{N} / \mathrm{P}$ ratio and toxicity), different species (i.e., maximize yields and control contamination), and technologies for cultivation (i.e., enough reactor mixing and economic infra-structure), in order to better understand the potentials, risks, and bottlenecks to scale up such technologies.

\section{CONCLUSIONS}

This study assessed the cultivation of microalgae and cyanobacteria in wastewater to recover high-value bioproducts and bioenergy from residual biomass. The cyanobacteriadominated mixed culture grown in treated wastewater (secondary effluent) and anaerobic digestion centrate achieved removal efficiencies up to $52 \%$ of COD, $86 \%$ of $\mathrm{NH}_{4}{ }^{+}-\mathrm{N}$, and $100 \%$ of phosphorus.

Phycocyanin and phycoerythrin were extracted from harvested biomass reaching concentrations up to 20.1 and $8.1 \mathrm{mg} / \mathrm{g}$ dry weight, respectively. Biogas was then recovered from residual biomass, reaching up to $199 \mathrm{~mL} \mathrm{CH}_{4} / \mathrm{g}$ VS. The use of wastewater was shown to be appropriate to produce high-value bioproducts and recover bioenergy, while reducing biomass production costs.

\section{ASSOCIATED CONTENT}

\section{sI Supporting Information}

The Supporting Information is available free of charge at https://pubs.acs.org/doi/10.1021/acssuschemeng.0c01106.

Characterization of influent streams used to feed the photobioreactors: secondary effluent, centrate, and digestate; cell counting method (PDF)

\section{AUTHOR INFORMATION}

\section{Corresponding Author}

Ivet Ferrer - GEMMA - Group of Environmental Engineering and Microbiology, Department of Civil and Environmental Engineering, Universitat Politènica de Catalunya . BarcelonaTech, 08034 Barcelona, Spain; ㅈorcid.org/00000002-4568-4843; Phone: +34 934016463;

Email: ivet.ferrer@upc.edu

\section{Authors}

Larissa T. Arashiro - GEMMA - Group of Environmental Engineering and Microbiology, Department of Civil and Environmental Engineering, Universitat Politécnica de Catalunya - BarcelonaTech, 08034 Barcelona, Spain; Laboratory for Industrial Water and Ecotechnology (LIWET), Department of Green Chemistry and Technology, Ghent University Campus Kortrijk, B-8500 Kortrijk, Belgium

Catalina C. Pániker - GEMMA - Group of Environmental Engineering and Microbiology, Department of Civil and Environmental Engineering, Universitat Politecnica de Catalunya $\cdot$ BarcelonaTech, 08034 Barcelona, Spain

Juan Luis Gómez-Pinchetti - Spanish Bank of Algae, Institute of Oceanography and Global Change, University of Las Palmas de Gran Canaria, Muelle de Taliarte 35214, Canary Islands, Spain

Diederik P. L. Rousseau - Laboratory for Industrial Water and Ecotechnology (LIWET), Department of Green Chemistry and Technology, Ghent University Campus Kortrijk, B-8500 Kortrijk, Belgium

Stijn W. H. Van Hulle - Laboratory for Industrial Water and Ecotechnology (LIWET), Department of Green Chemistry and Technology, Ghent University Campus Kortrijk, B-8500 Kortrijk, Belgium 
Marianna Garfí - GEMMA - Group of Environmental Engineering and Microbiology, Department of Civil and Environmental Engineering, Universitat Politecnica de Catalunya $\cdot$ BarcelonaTech, 08034 Barcelona, Spain

Complete contact information is available at: https://pubs.acs.org/10.1021/acssuschemeng.0c01106

\section{Notes}

The authors declare no competing financial interest.

\section{ACKNOWLEDGMENTS}

This research was funded by the European Union's Horizon 2020 research and innovation programme under the Marie Skłodowska-Curie Grant Agreement No 676070 (SuPER-W). This communication reflects only the author's view and the Research Executive Agency of the EU is not responsible for any use that may be made of the information it contains. Authors acknowledge the AL4BIO project "RTI2018-099495B-C21" (MCIU/AEI/FEDER, UE) and are grateful to the Government of Catalonia (Consolidated Research Group 2017 SGR 1029). Marianna Garfi is grateful to the MINECO (RYC-2016-20059). Authors acknowledge Antera Martel, Mireia Sánchez, and Noelia Robles from the Spanish Bank of Algae for their helpful assistance with microalgae species identification and phycobiliproteins extraction. Authors are also thankful to Carme Maynés, Izia Lena and Caroline Bayeux for their contribution.

\section{REFERENCES}

(1) Acién Fernández, F. G.; Gómez-Serrano, C.; Fernández-Sevilla, J. M. Recovery of Nutrients From Wastewaters Using Microalgae. Front. Sustain. Food Syst. 2018, 2, 1-13.

(2) Bhattacharya, S.; Pramanik, S. K.; Gehlot, P. S.; Patel, H.; Gajaria, T.; Mishra, S.; Kumar, A. Process for Preparing Value-Added Products from Microalgae Using Textile Effluent through a Biorefinery Approach. ACS Sustainable Chem. Eng. 2017, 5 (11), 10019-10028.

(3) Acién, F. G.; Gómez-Serrano, C.; Morales-Amaral, M. M.; Fernández-Sevilla, J. M.; Molina-Grima, E. Wastewater Treatment Using Microalgae: How Realistic a Contribution Might It Be to Significant Urban Wastewater Treatment? Appl. Microbiol. Biotechnol. 2016, 100 (21), 9013-9022.

(4) Pagels, F.; Guedes, A. C.; Amaro, H. M.; Kijjoa, A.; Vasconcelos, V. Phycobiliproteins from Cyanobacteria: Chemistry and Biotechnological Applications. Biotechnol. Adv. 2019, 37 (3), $422-443$.

(5) Cuellar-Bermudez, S. P.; Aguilar-Hernandez, I.; CardenasChavez, D. L.; Ornelas-Soto, N.; Romero-Ogawa, M. A.; ParraSaldivar, R. Extraction and Purification of High-Value Metabolites from Microalgae: Essential Lipids, Astaxanthin and Phycobiliproteins. Microb. Biotechnol. 2015, 8, 190.

(6) Noreña-Caro, D.; Benton, M. G. Cyanobacteria as Photoautotrophic Biofactories of High-Value Chemicals. J. CO2 Util. 2018, 28 (May), 335-366.

(7) Manirafasha, E.; Ndikubwimana, T.; Zeng, X.; Lu, Y.; Jing, K. Phycobiliprotein: Potential Microalgae Derived Pharmaceutical and Biological Reagent. Biochem. Eng. J. 2016, 109, 282-296.

(8) Luo, X.; Smith, P.; Raston, C. L.; Zhang, W. Vortex Fluidic Device-Intensified Aqueous Two Phase Extraction of C-Phycocyanin from Spirulina Maxima. ACS Sustainable Chem. Eng. 2016, 4 (7), 3905-3911.

(9) Ramos-Suárez, J. L.; Cuadra, F. G.; Acién, F. G.; Carreras, N. Benefits of Combining Anaerobic Digestion and Amino Acid Extraction from Microalgae. Chem. Eng. J. 2014, 258, 1-9.
(10) Gong, J.; You, F. Value-Added Chemicals from Microalgae: Greener, More Economical, or Both? ACS Sustainable Chem. Eng. 2015, 3 (1), 82-96.

(11) Van Den Hende, S.; Beyls, J.; De Buyck, P. J.; Rousseau, D. P. L. Food-Industry-Effluent-Grown Microalgal Bacterial Flocs as a Bioresource for High-Value Phycochemicals and Biogas. Algal Res. 2016, 18, 25-32.

(12) Yen, H.-W.; Hu, I.-C.; Chen, C.-Y.; Ho, S.-H.; Lee, D.-J.; Chang, J.-S. Microalgae-Based Biorefinery - From Biofuels to Natural Products. Bioresour. Technol. 2013, 135, 166-174.

(13) Vulsteke, E.; Van Den Hende, S.; Bourez, L.; Capoen, H.; Rousseau, D. P. L.; Albrecht, J. Economic Feasibility of Microalgal Bacterial Floc Production for Wastewater Treatment and Biomass Valorization: A Detailed up-to-Date Analysis of up-Scaled Pilot Results. Bioresour. Technol. 2017, 224, 118-129.

(14) Khatoon, H.; Kok Leong, L.; Abdu Rahman, N.; Mian, S.; Begum, H.; Banerjee, S.; Endut, A. Effects of Different Light Source and Media on Growth and Production of Phycobiliprotein from Freshwater Cyanobacteria. Bioresour. Technol. 2018, 249, 652-658.

(15) Wood, J. L.; Miller, C. D.; Sims, R. C.; Takemoto, J. Y. Biomass and Phycocyanin Production from Cyanobacteria Dominated Bio Fi Lm Reactors Cultured Using Oil Fi Eld and Natural Gas Extraction Produced Water. Algal Res. 2015, 11, 165-168.

(16) Arashiro, L. T.; Boto-Ordóñez, M.; Van Hulle, S. W. H.; Ferrer, I.; Garfí, M.; Rousseau, D. P. L. Natural Pigments from Microalgae Grown in Industrial Wastewater. Bioresour. Technol. 2020, 303, 122894.

(17) Xie, B.; Gong, W.; Tang, X.; Bai, L.; Guo, Y.; Wang, J.; Zhao, J.; Fan, Y.; Li, G.; Liang, H. Blending High Concentration of Anaerobic Digestion Effluent and Rainwater for Cost-Effective Chlorella Vulgaris Cultivation in the Photobioreactor. Chem. Eng. J. 2019, 360, 861-865.

(18) Praveen, P.; Guo, Y.; Kang, H.; Lefebvre, C.; Loh, K. Enhancing Microalgae Cultivation in Anaerobic Digestate through Nitrification. Chem. Eng. J. 2018, 354 (June), 905-912.

(19) Ge, S.; Qiu, S.; Tremblay, D.; Viner, K.; Champagne, P.; Jessop, P. G. Centrate Wastewater Treatment with Chlorella Vulgaris: Simultaneous Enhancement of Nutrient Removal, Biomass and Lipid Production. Chem. Eng. J. 2018, 342, 310-320.

(20) Arias, D. M.; Solé-Bundó, M.; Garfí, M.; Uggetti, E.; Ferrer, I.; García, J. Integrating Microalgae Tertiary Treatment into Activated Sludge Systems for Energy and Nutrients Recovery from Wastewater. Bioresour. Technol. 2018, 247, 513-519.

(21) Cheunbarn, S.; Peerapornpisal, Y. Cultivation of Spirulina Platensis Using Anaerobically Swine Wastewater Treatment Effluent. Int. J. Agric. Biol. 2010, 12 (4), 586-590.

(22) Arias, D. M.; Uggetti, E.; García-Galán, M. J.; García, J. Production of Polyhydroxybutyrates and Carbohydrates in a Mixed Cyanobacterial Culture: Effect of Nutrients Limitation and Photoperiods. New Biotechnol. 2018, 42, 1-11.

(23) Arias, D. M.; Uggetti, E.; García-Galán, M. J.; García, J. Cultivation and Selection of Cyanobacteria in a Closed Photobioreactor Used for Secondary Effluent and Digestate Treatment. Sci. Total Environ. 2017, 587-588, 157-167.

(24) Arias, D. M.; Uggetti, E.; García, J. Assessing the Potential of Soil Cyanobacteria for Simultaneous Wastewater Treatment and Carbohydrate-Enriched Biomass Production. Algal Res. (Manuscript submitted for publication).

(25) Arashiro, L. T.; Ferrer, I.; Rousseau, D. P.L.; Van Hulle, S. W.H.; Garfi, M. The Effect of Primary Treatment of Wastewater in High Rate Algal Pond Systems: Biomass and Bioenergy Recovery. Bioresour. Technol. 2019, 280, 27-36.

(26) Uggetti, E.; García, J.; Álvarez, J. A.; García-Galán, M. J. Startup of a Microalgae-Based Treatment System within the Biorefinery Concept: From Wastewater to Bioproducts. Water Sci. Technol. 2018, 78 (1), 114-124.

(27) Arias, D. M.; Rueda, E.; García-Galán, M. J.; Uggetti, E.; García, J. Selection of Cyanobacteria over Green Algae in a Photo- 
Sequencing Batch Bioreactor Fed with Wastewater. Sci. Total Environ. 2019, 653, 485-495.

(28) Guillard, R. R. L.; Sieracki, M. S. Counting Cells in Light Microscopy. Algal Culturing Techniques; Phycological Society: Hong Kong, 2005; pp 239-252.

(29) Streble, H.; Krauter, D. Atlas de los microorganismos de agua dulce, La vida en una gota de agua; Omega: Barcelona, 1987.

(30) Komárek, J.; Kaštovský, J.; Mareš, J.; Johansen, J. R. Taxonomic Classification of Cyanoprokaryotes (Cyanobacterial Genera) 2014, Using a Polyphasic Approach Taxonomické Hodnoceni Cyanoprokaryot (Cyanobakteriálni Rody) v Roce 2014 Podle Polyfázického Pŕistupu. Preslia 2014, 86, 295-335.

(31) Patel, A.; Mishra, S.; Pawar, R.; Ghosh, P. K. Purification and Characterization of C-Phycocyanin from Cyanobacterial Species of Marine and Freshwater Habitat. Protein Expression Purif. 2005, 40 (2), 248-255.

(32) Ores, J. da C.; Amarante, M. C. A. de; Kalil, S. J. CoProduction of Carbonic Anhydrase and Phycobiliproteins by Spirulina Sp. and Synechococcus Nidulans. Bioresour. Technol. 2016, 219, 219-227.

(33) APHA/AWWA/WEF Standard Methods for the Examination of Water and Wastewater. Stand. Methods, 2012; https://doi.org/ ISBN 9780875532356.

(34) Kamble, S. P.; Gaikar, R. B.; Padalia, R. B.; Shinde, K. D. Extraction and Purification of C-Phycocyanin from Dry Spirulina Powder and Evaluating Its Antioxidant, Anticoagulation and Prevention of DNA Damage Activity. J. Appl. Pharm. Sci. 2013, 3 (8), 149-153.

(35) Furuki, T.; Maeda, S.; Imajo, S.; Hiroi, T.; Amaya, T.; Hirokawa, T.; Ito, K.; Nozawa, H. Rapid and Selective Extraction of Phycocyanin from Spirulina Platensis with Ultrasonic Cell Disruption. J. Appl. Phycol. 2003, 15 (4), 319-324.

(36) Bennett, A.; Bogorad, L. Complementary Chromatic Adaptation in a Filamentous Blue-Green Alga. J. Cell Biol. 1973, 58 (2), 419-435.

(37) Solé-Bundó, M.; Salvadó, H.; Passos, F.; Garfí, M.; Ferrer, I. Strategies to Optimize Microalgae Conversion to Biogas: CoDigestion, Pretreatment and Hydraulic Retention Time. Molecules 2018, 23 (9), 2096.

(38) Chernicharo, C. A. de L. Anaerobic Reactors; IWA Publishing, 2007.

(39) Solórzano, L. Determination of Ammonia in Natural Seawater by the Phenol-Hypochlorite Method. Limnol. Oceanogr. 1969, 14 (5), 799-801.

(40) Schroyen, M.; Vervaeren, H.; Van Hulle, S. W. H.; Raes, K. Impact of Enzymatic Pretreatment on Corn Stover Degradation and Biogas Production. Bioresour. Technol. 2014, 173, 59-66.

(41) Directive 98/15/EC, D. Directive 98/15/EC, 1998. 98/15/EC of 27 February.

(42) de Godos, I.; Vargas, V. A.; Guzmán, H. O.; Soto, R.; García, B.; García, P. A.; Muñoz, R. Assessing Carbon and Nitrogen Removal in a Novel Anoxic e Aerobic Cyanobacterial e Bacterial Photobioreactor Configuration with Enhanced Biomass Sedimentation. Water Res. 2014, 61, 77-85.

(43) Ruiz-Marin, A.; Mendoza-Espinosa, L. G.; Stephenson, T. Growth and Nutrient Removal in Free and Immobilized Green Algae in Batch and Semi-Continuous Cultures Treating Real Wastewater. Bioresour. Technol. 2010, 101 (1), 58-64.

(44) Pruvost, J.; Le Gouic, B.; Lepine, O.; Legrand, J.; Le Borgne, F. Microalgae Culture in Building-Integrated Photobioreactors: Biomass Production Modelling and Energetic Analysis. Chem. Eng. J. 2016, 284, 850-861.

(45) Day, J. G.; Gong, Y.; Hu, Q. Microzooplanktonic Grazers - A Potentially Devastating Threat to the Commercial Success of Microalgal Mass Culture. Algal Res. 2017, 27, 356-365.

(46) Fagundes, M. B.; Vendruscolo, R. G.; Maroneze, M. M.; Barin, J. S.; de Menezes, C. R.; Zepka, L. Q.; Jacob-Lopes, E.; Wagner, R. Towards a Sustainable Route for the Production of Squalene Using Cyanobacteria. Waste Biomass Valorization 2019, 10 (5), 1295-1302.
(47) Chakdar, H.; Pabbi, S. In Algal Pigments for Human Health and Cosmeceuticals; Rastogi, R. P., Madamwar, D., Pandey, A. B. T.-A. G. C., Eds.; Elsevier: Amsterdam, 2017; pp 171-188.

(48) Borowitzka, M. A. High-Value Products from Microalgae-Their Development and Commercialisation. J. Appl. Phycol. 2013, 25 (3), $743-756$.

(49) Jankowska, E.; Sahu, A. K.; Oleskowicz-Popiel, P. Biogas from Microalgae: Review on Microalgae's Cultivation, Harvesting and Pretreatment for Anaerobic Digestion. Renewable Sustainable Energy Rev. 2017, 75, 692-709.

(50) Arashiro, L. T.; Montero, N.; Ferrer, I.; Acién, F. G.; Gómez, C.; Garfí, M. Life Cycle Assessment of High Rate Algal Ponds for Wastewater Treatment and Resource Recovery. Sci. Total Environ. 2018, 622-623, 1118.

(51) Mudimu, O.; Rybalka, N.; Bauersachs, T.; Born, J.; Friedl, T.; Schulz, R. Biotechnological Screening of Microalgal and Cyanobacterial Strains for Biogas Production and Antibacterial and Antifungal Effects. Metabolites 2014, 4 (2), 373-393.

(52) Bessette, A. P.; Stuart, B. J.; Resurreccion, E. P.; Kumar, S. Algae-Powered Sustainable Community Design Life Cycle Assessment and Techno-Economic Analysis. ACS Sustainable Chem. Eng. 2020, 8, 1916-1922.

(53) Ferrándiz, M.; Moldovan, S.; Mira, E.; Pinchetti, J. L. G.; Rodriguez, T.; Abreu, H.; Rego, A. M.; Palomo, B.; Caro, P. Phycobiliproteins - New Natural Dyes from Algae as a Sustainable Method. In Special issue venue XXIV International Congress IFATCC 2016, 56-61.

(54) Moldovan, S.; Ferrandiz, M.; Franco, E.; Mira, E.; Capablanca, L.; Bonet, M. Printing of Cotton with Eco-Friendly, Red Algal Pigment from Gracilaria Sp. In IOP Conference Series: Materials Science and Engineering; 2017; Vol. 254.

(55) Vuppaladadiyam, A. K.; Prinsen, P.; Raheem, A.; Luque, R.; Zhao, M. Sustainability Analysis of Microalgae Production Systems: A Review on Resource with Unexploited High-Value Reserves. Environ. Sci. Technol. 2018, 52 (24), 14031-14049.

(56) Raheem, A.; Prinsen, P.; Vuppaladadiyam, A. K.; Zhao, M.; Luque, R. A Review on Sustainable Microalgae Based Biofuel and Bioenergy Production: Recent Developments. J. Cleaner Prod. 2018, 181, 42-59. 